PROCEDURE FOR THE PRODUCTION OF DYNAMIC PRE-KNEE ORTHOSIS USING THE UNILATERAL SYSTEM

Branko Stefanovic; Monika Michalikova; Lucia Bednarcikova; Marianna Trebunova; Jozef Zivcak

\title{
PROCEDURE FOR THE PRODUCTION OF DYNAMIC PRE-KNEE ORTHOSIS USING THE UNILATERAL SYSTEM
}

\author{
Branko Stefanovic \\ Technical University of Košice, Department of Biomedical Engineering and Measurement, Letna 9, 04200 Košice, \\ Slovak Republic, EU, branko.stefanovic@tuke.sk \\ Monika Michalikova \\ Technical University of Košice, Department of Biomedical Engineering and Measurement, Letna 9, 04200 Košice, \\ Slovak Republic, EU, monika.michalikova@tuke.sk

\section{Lucia Bednarcikova} \\ Technical University of Košice, Department of Biomedical Engineering and Measurement, Letna 9, 04200 Košice, \\ Slovak Republic, EU, lucia.bednarcikova@tuke.sk

\section{Marianna Trebunova} \\ Technical University of Košice, Department of Biomedical Engineering and Measurement, Letna 9, 04200 Košice, \\ Slovak Republic, EU, marianna.trebunova@tuke.sk (corresponding author)

\section{Jozef Zivcak} \\ Technical University of Košice, Department of Biomedical Engineering and Measurement, Letna 9, 04200 Košice, \\ Slovak Republic, EU, jozef.zivcak@tuke.sk
}

Keywords: pre-knee brace, dynamic brace, structural design Abstract: The article deals with the design of an orthotic solution of dynamic knee orthoses for patients after polio. The aim was to design and create an orthopedic device and describe the technological process of its production. The design, testing and production of the orthosis aim to ensure the physiological position of the foot, to perform plantar and dorsal flexion in the ankle and to verticalize the position of the entire lower limb. These parameters have a considerable impact on maintaining posture, balance, walking stability and locomotion as well as elimination of inappropriate pathological movement habits. The results of orthotherapy show that their use corrects the course of the physiological axis in all planes. The corrected lower limb axis significantly affects the supportive, balance, and allocating ability of individuals.

\section{Introduction}

At present, the issue of damage to the human musculoskeletal system is increasingly monitored. In terms of the incidence of congenital disorders, an increased number of post-traumatic cases following accidents or injuries, e.g. in traffic accidents, extreme sports, etc., but also in connection with the aging of the population, the demand for orthotic-prosthetic solutions is increasing over time. The phenomenon of aging concerns not only local regions, but also becomes a pan-European and global challenge. Disorders of the musculoskeletal system and deviations from the physiological state thus concern each of us. The impact of lifestyle changes is an integral part of human development and adversely affects the body. It is the changes and diseases of the musculoskeletal system that are closely interconnected with other systems and interact with each other. Orthotics is a narrower specialization of orthopedic prosthetics, which deals with the issue of methods of replacement, or adjustment of lost or weakened functions, prevention and correction of deformities of the musculoskeletal system. The proposal of a particular type of orthosis is processed by an orthopedic technician on the basis of a doctor's recommendation, professional knowledge, skills, and own experience. The final solution is therefore not only dependent on professional competence, but also on a lot of knowledge and examination of professional engineers in the field. This article presents theoretical knowledge of orthotic treatment of knee and ankle disorders by means of dynamic orthoses, as well as practical examples of a particular case - the application of pre-knee dynamic orthosis for a patient after polio.

\section{Materials and methods}

The article presents two male subjects aged 16 and 18 with dynamic pre-knee braces. Both subjects in childhood have overcome the infectious disease poliomyelitis that attacks the central nervous system (brain and / or spinal cord) [1]. $0.1 \%$ of the total number of infections present with permanent paralysis. In these patients, symptoms of post-poliomyelitic syndrome of both lower limbs appear as a result of the disease. Typical images of disability are valgus position of the knees in the frontal plane, hyperextension in the knee joints (Figure 1), dorsal resp. plantar extension of the hinge joints in the sagittal plane [2]. Subjects also exhibit other symptoms such as increased muscle weakness and joint muscle pain, decreased muscle mass (muscular atrophy), increased joint instability / joint deformities and changes in gait patterns, and an increased tendency to fall [3]. All of the above symptoms have a 
profound effect on the ability to maintain proper posture, balance, gait stability, locomotion as well as the formation of inappropriate pathological movement habits. The present goal is to achieve an improvement in the static attitude and mobility of these subjects by an orthotic solution [4].

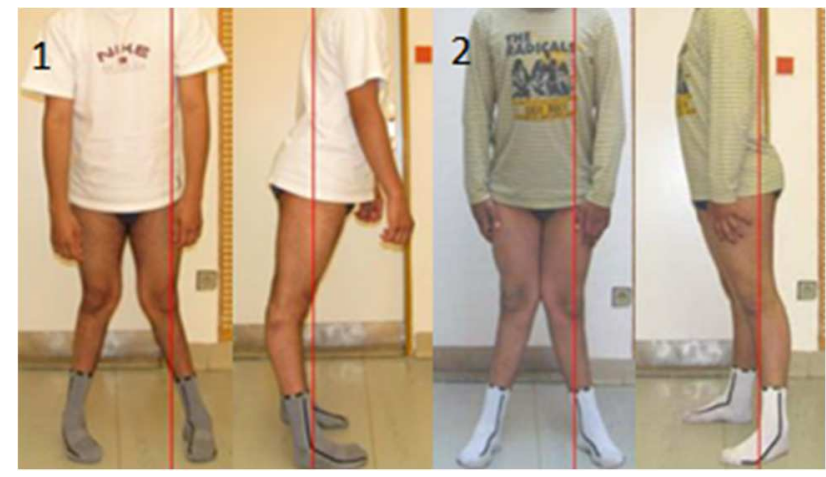

Figure 1 Baseline - front side view, subject 1 (left), subject 2 (right)

\section{Production of dynamic knee brace}

Based on the diagnosis, orthopedic device in the form of dynamic knee orthosis was indicated to both subjects [5]6].

To produce an orthopedic device, it is necessary to measure selected knee length, width and circumferential dimensions by appropriate measuring aids, such as: knee length, knee width, ankle joint width, heel to toe length, forefoot width, foot angle to medial / lateral side, limb circumference - $10 \mathrm{~cm}$ above the patella, knee circumference, maximum calf circumference and ankle circumference. If limb discrepancy is present, the limb truncation value should be recorded [7].

After obtaining the necessary dimensional data, the preparation for plastering is started. In this phase of orthopedic device construction, important a line construction points, such as the compromise centre of rotation in the knee joint and the fibula head, are plotted on the limb, which is a load-sensitive location. Other important points are the compromise centre of rotation in the ankle joint, various growths, bone protrusions, painful spots and patella position. On the basis of these substrates a gypsum negative is made by a three-phase procedure (foot negative, knee negative, knee negative) [7].

To keep the load line and the exact location of the orthotic joint, it is advisable to use a plaster stand in which the plaster negative of the lower limb is clamped. The position is corrected on the stand. After all the necessary steps have been taken, the gypsum negates and the gypsum positive (Figure 2) is produced, which must be subsequently treated (correction of casting errors, loadable and nonloadable areas) [7].

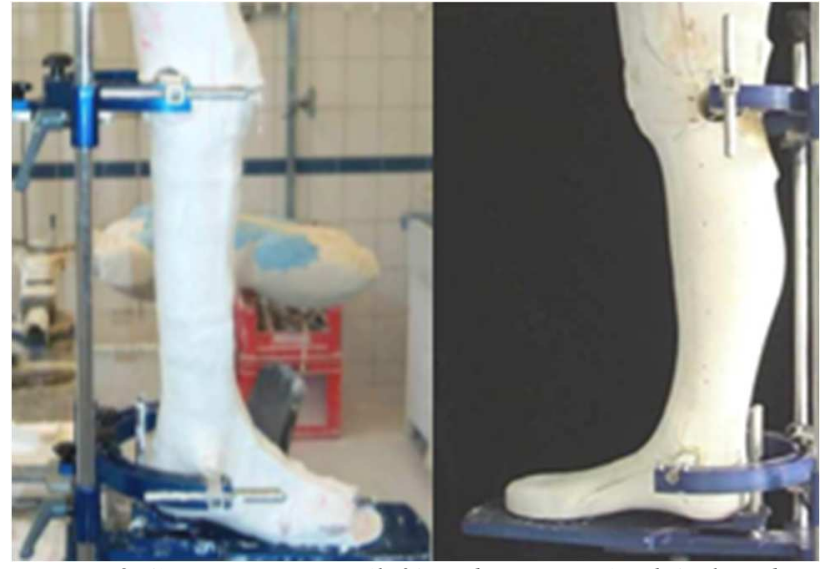

Figure 2 Gypsum negative (left) and positives (right) placed in the orthosis stand

\subsection{Production of a test orthosis}

On the corrected and treated positive, a test orthosis shell (Figure 3) is formed by stretching the high temperature polypropylene thermoplastic heated to $185^{\circ} \mathrm{C}$ with the aid of vacuum suction. For the use of the unilateral lower limb orthosis system, components that are manufactured and classified by patient weight are used. Following are adjustments for the placement of the orthotic joint, shaping the plates, marking the lines of the sleeve edges. The sleeves are removed from the gypsum model and their edges are ground by means of a cylindrical grinder and the surface is smoothed. In the treatment of the longitudinal and angular discrepancies of the limbs, the production of a heel for correction is made by pouring the foil Pedilin, which cures into a solid form. After the foam has hardened, it is ground to the required size, taking into account the axial position of the foot [7].

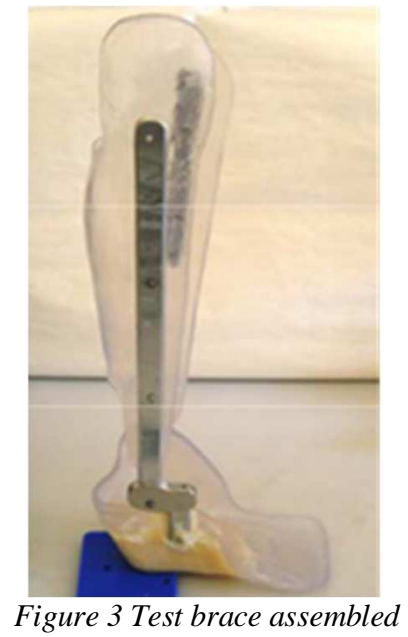

\subsection{Testing of the orthosis}

Testing (Figure 4) is carried out in active cooperation between the patient and the technician. The patient is assessed at the frontal and sagittal levels after standing and walking [8]. In this phase the orthosis deficiencies are 
eliminated, e.g. the degree of dorsal and plantar flexion, the dimensions of the device and the placement of the limb of the orthosis. The test orthosis will be marked with points which are unnecessary in support and may be removed. The openings are important in terms of breathability and overall comfort when wearing the orthosis daily [7].

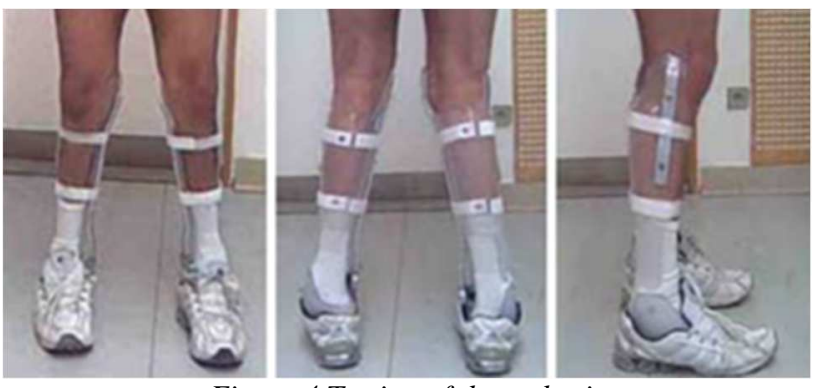

Figure 4 Testing of the orthosis

\subsection{Production of a definitive orthosis}

The sleeve of the definite knee brace is made to a great extent from composite materials and therefore lamination is used for its production. The auxiliary lines that have been marked on the test sleeves are transferred to the plaster model or, if necessary, made on a positive basis as needed. This is followed by reinforcing the areas that are most stressed with carbon tape (Figure 5). It is mainly the padding of the foot in the plantar part of the heel and the knee in the area of the support areas. Only after checking the position of the splints and reinforcements, does the lamination with laminating resin and hardener continue [7].

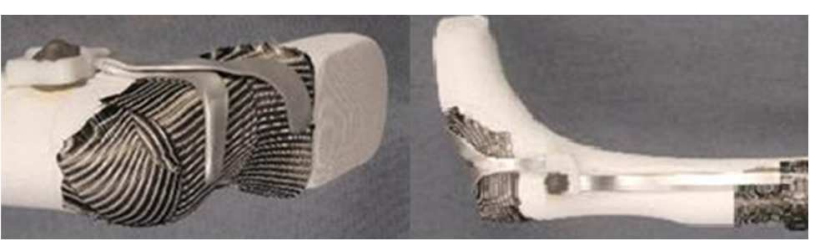

Figure 5 Placing the reinforcing fabric before laminating

The laminating mixture is cured under pressure. After marking the cutting edges, the sleeve is ground and smoothed using a vibrating saw. The laminating tool is removed from the ankle area and replaced with the appropriate ankle insert according to the desired plantar resp. dorsal flexion. The orthosis is completed by fastening through the knee, but also above the ankle, as required (Figure 6) [7].

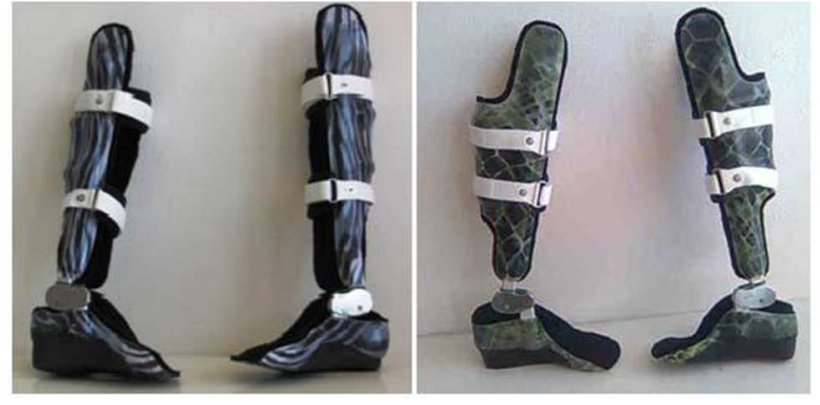

Figure 6 Definitive knee braces - Subject 1 and subject 2

\section{Results of orthotherapy}

Prior to the application of the dynamic pre-knee orthosis, a significant valgus of the knees is present in the subject, causing a compensatory position in the ankle joint region. As can be seen, the course of the gravity line in the frontal plane does not correspond to the physiological lines, which is also evident in the symmetrical position of the arms (Figure 7, Figure 8). Prolonged posture with enlarged compensatory lordosis of the lumbar spine and tilt of the pelvis in the PA direction is due to hyperextension of the knee joints and subsequent plantar flexion of the ankles that are observed in the sagittal plane. The gravity line in the sagittal plane in both patients does not run physiologically and affects the maintenance of equilibrium and subsequent stability during standing. This position, however, significantly affects the locomotion pattern of motion and prediction of frequent falls. The following application of dynamic pre-knee orthosis, the following figures clearly show the effect of orthotherapy on body posture, posture stability and hence on locomotion ability. This graphical documentation depicts two polio patients whose medical treatment and rehabilitation have been supplemented by the selection, manufacture and application of a suitable dynamic orthosis. Patients agreed to create photo documentation and its publishing. The pictures on the left show a uniform status of the patient before and after the application of the dynamic orthosis, in the real-life testing process. 
Branko Stefanovic; Monika Michalikova; Lucia Bednarcikova; Marianna Trebunova; Jozef Zivcak

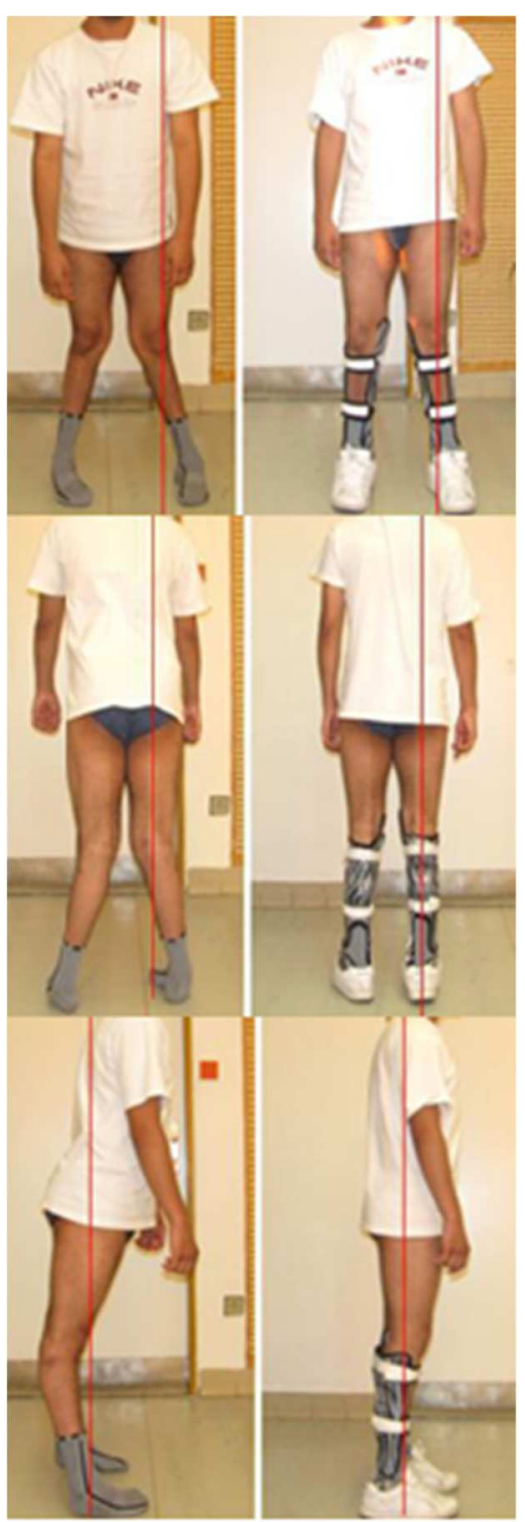

Figure 7 Subject 1, anterior, posterior, side view without and with the aid of an applied knee brace.

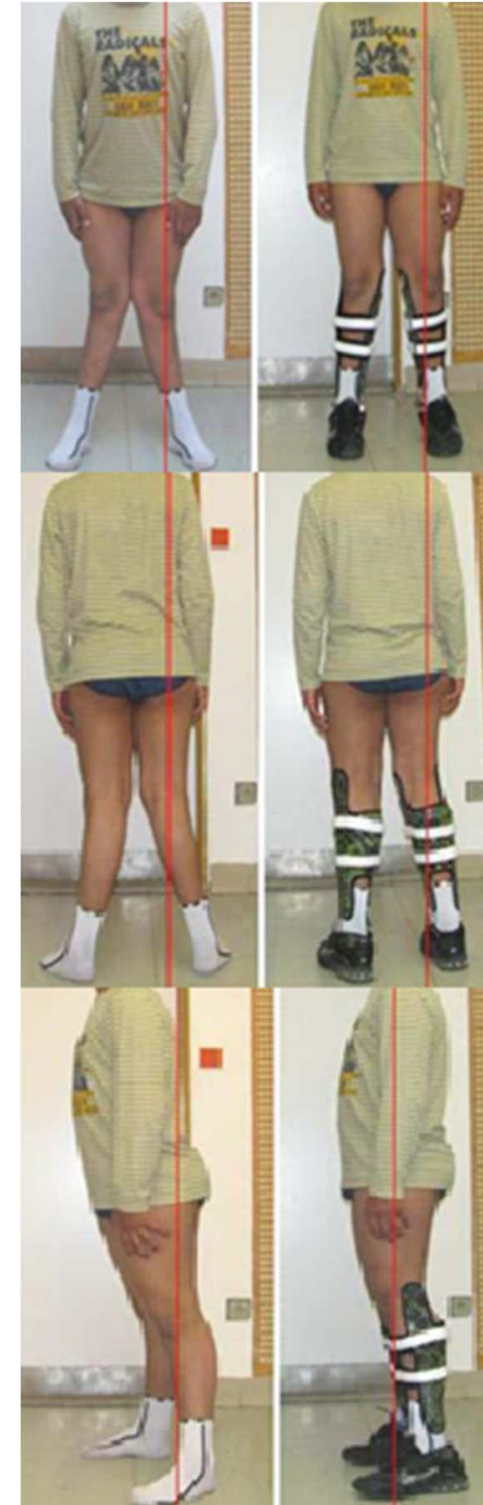

Figure 8 Subject 2, anterior, posterior, side view without and with the aid of an applied knee brace.

\section{Conclusions}

The aim of this paper was to describe a particular orthotic solution and optimization of the methodical procedure - design and technological procedure in the application of dynamic knee orthosis for patients after polio. These case studies offer a representative sample of the effect of orthopedic devices. The above-mentioned photo documentation offers an overview and a clear idea of the effect of these orthotic devices. There is an obvious correction of the position of the lower limbs and thus improvement of the overall posture of the individuals. By examining the entire process of designing, developing and applying the orthosis, from the patient's arrival to the prosthetic centre until the definitive orthosis becomes the client's daily aid, one can learn about the results and procedures in orthotic practice. 
PROCEDURE FOR THE PRODUCTION OF DYNAMIC PRE-KNEE ORTHOSIS USING THE UNILATERAL

Branko Stefanovic; Monika Michalikova; Lucia Bednarcikova; Marianna Trebunova; Jozef Zivcak

\section{Acknowledgements}

This article was supported by the state grants: VEGA 1/0316/16, KEGA 041TUKE-4/2019 and 023TUKE4/2020 and APVV-19-0290.

\section{References}

[1] MENANT, J., GANDEVIA, S.: Handbook of Clinical Neurology, Chapter 21 -Poliomyelitis, Elsevier, Vol. $159,2018$.

[2] ŽIVČÁK, J., et al: Biomechanika človeka I., Human biomechanics I., 1st edition, Prešov, Grafotlač Prešov, 2007. (Original in Slovak)

[3] GENÊT, F., SCHNITZLER, A., MATHIEU, S., AUTRET, K., THÉFENNE, L., DIZIEN, O., MALDJIAN, A.: Orthotic devices and gait in polio patients, Annals of Physical and Rehabilitation Medicine, Vol. 53, No. 1, pp. 51-59, 2009. doi:10.1016/j.rehab.2009.11.005

[4] O'CONNOR, J., MCCAUGHAN, D., MCDAID, C., BOOTH, A:, FAYTER, D., RODRIGUEZ-LOPEZ, R., BOWERS, R., DYSON, L., IGLESIAS, C.P., LALOR, S., O'CONNOR, R.J., HILLIPS, M., RAMDHARRY, G.: Orthotic management of instability of the knee related to neuromuscular and central nervous system disorders: Systematic review, qualitative study, survey and costing analysis, Health technology assessment, Vol. 20, No. 55, pp. 1-262, 2016. doi:10.3310/hta20550

[5] MORRIS, C., CONDIE, D., (ed): Recent Developments in Healthcare for Cerebral Palsy, Implications and Opportunities for Orthotics, Copenhagen, International Society for Prosthetics and Orthotics, 2009.

[6] ARNDT, A., FRÖBERG, A., MÅRTENSSON, M.: The Effect of Ankle Foot Orthosis' Design and Degree of Dorsiflexion on Achilles Tendon BiomechanicsTendon Displacement, Lower Leg Muscle Activation, and Plantar Pressure During Walking, Frontiers in Sports and Active Living, Switzerland, Frontiers Media SA, Vol. 2, No. March, Article 16, pp. 1-10, 2020. doi:10.3389/fspor.2020.00016

[7] IHNATKO, L.: Dynamické predkolenné ortézy, Dynamic below-knee orthesis, Bachelor thesis, Košice, Technical university of Košice, Faculty of mechanical engineering, 2009. (Original in Slovak)

[8] THEODORAKOS, I., RUETERBORIES, J., LUND, M., ANDERSEN, M.S., de ZEE, M., KERSTING, U.G.: Ankle bracing effects on knee and hip mechanics during landing on inclined surfaces, International Biomechanics, Vol. 3, No. 1, pp. 22-32, 2016. doi:10.1080/23335432.2015.1132638

\section{Review process}

Single-blind peer review process. 